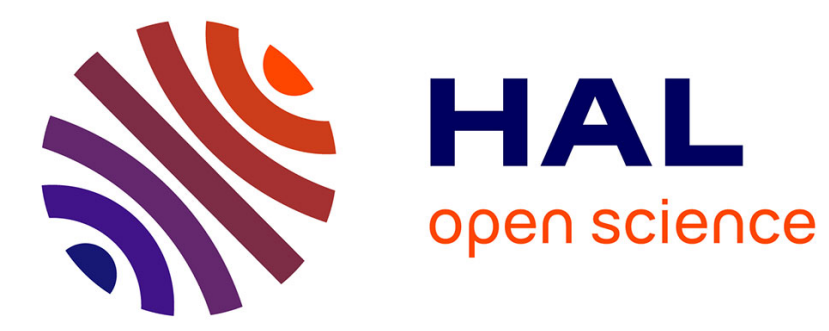

\title{
Contactless mapping of lifetime and diffusion length scan map of minority carriers in silicon wafers
}

\author{
O. Palais, J. Gervais, E. Yakimov, S. Martinuzzi
}

\section{To cite this version:}

O. Palais, J. Gervais, E. Yakimov, S. Martinuzzi. Contactless mapping of lifetime and diffusion length scan map of minority carriers in silicon wafers. European Physical Journal: Applied Physics, 2000, 10 (2), pp.157-162. 10.1051/epjap:2000128 . hal-03350321

\section{HAL Id: hal-03350321 \\ https://hal-amu.archives-ouvertes.fr/hal-03350321}

Submitted on 22 Sep 2021

HAL is a multi-disciplinary open access archive for the deposit and dissemination of scientific research documents, whether they are published or not. The documents may come from teaching and research institutions in France or abroad, or from public or private research centers.
L'archive ouverte pluridisciplinaire HAL, est destinée au dépôt et à la diffusion de documents scientifiques de niveau recherche, publiés ou non, émanant des établissements d'enseignement et de recherche français ou étrangers, des laboratoires publics ou privés. 


\title{
Contactless mapping of lifetime and diffusion length scan map of minority carriers in silicon wafers
}

\author{
O. Palais, J. Gervais, E. Yakimov, and S. Martinuzzi ${ }^{\mathrm{a}}$ \\ Laboratoire de Photoélectricité LPDSO ${ }^{\mathrm{b}}$, Université de Marseilles, 13397 Marseille Cedex 20, France
}

Received: 17 September 1999 / Revised: 3 February 2000 / Accepted: 17 March 2000

\begin{abstract}
The lifetime of minority carriers in crystalline silicon wafers is determined by means of the contactless microwave phase-shift technique, when the surfaces of the samples are passivated using an iodine aqueous solution of polyvidone. The stability of the passivation is sufficient in order to obtain a lifetime scan map with spatial resolution of $50 \mu \mathrm{m}$, using a thin coaxial cable which directs $9.4 \mathrm{GHz}$ microwaves onto the investigated samples and a fiber coupled laser diode which generates carriers in excess. In gold contaminated single crystals an acceptable correlation is found between the lifetime scan maps and the local concentrations of gold determined by deep level transient spectroscopy applied to an array of aluminium silicon diodes. For multicrystalline silicon wafers containing large densities of different extended crystallographic defects, a good correlation is obtained between the lifetime maps and the diffusion length maps obtained by the light beam induced current technique. Both the maps display the same features of extended crystallographic defects and are in agreement with optical micrographs of the scanned samples after they have been chemically etched.
\end{abstract}

PACS. 42.70.-a Optical materials - 72.20.Jv Charge carriers: generation, recombination, lifetime, and trapping

\section{Introduction}

The lifetime $(\tau)$ of minority carriers in excess is one of the most important parameters for the characterization of semiconductor wafers used in the preparation of power devices and photovoltaic solar cells. When non homogeneous samples are involved, such as multicrystalline silicon wafers (mc-Si) and precipitates containing silicon single crystals, however, it is also sometimes necessary to establish scan maps of this lifetime.

Such maps could be deduced from minority carrier diffusion length $(L)$ maps obtained by means of the surface photovoltage (SPV) technique [1]. It is however also necessary to know the carrier diffusion coefficients as well as the spectral variation of the optical absorption coefficient $\left(\alpha_{\lambda}\right)$. Since $\alpha_{\lambda}$ is under the influence of the stress of the wafers, (influence which cannot always be exactly defined), it is very often preferable to measure $\tau$ directly Moreover, the techniques used to determine $L$ need metal depositions to create contacts and collecting structures. These depositions will have to be removed later, as they hinder the manufacture of the devices. They can also contaminate the wafers. That is why contactless methods involving microwaves are used nowadays, among which the photoconductance decay (PCD) technique is the most

\footnotetext{
a e-mail: santo.martinuzzi@DSO.U-3mrs.fr

b EA 2192
}

commonly used. Little study has been devoted to the contactless phase shift (PS) technique [2-5] which uses the phase shift $\phi$ between a sinusoidal modulation of the excitation and the variation of the reflection power of microwaves.

However, since recombinations occur in the bulk as well as on both surfaces of the samples the measured lifetime is in fact an effective lifetime $\left(\tau_{\text {eff }}\right)$, which depends on the bulk lifetime $\left(\tau_{\mathrm{b}}\right)$ and on the surface recombination velocity $S$, which itself depends strongly on the injection level.

To obtain $\tau_{\mathrm{b}}$, it is necessary to control $S$ by means of surface passivation techniques in which the material is not modified by high temperature annealing. It is advisable not to use thermal oxidation as the processing temperatures must be higher than $800{ }^{\circ} \mathrm{C}$. Deposition of a silicon nitride layer by plasma enhanced chemical vapor deposition is a more likely process [4] - this layer will have to be removed afterwards to make the devices.

A very efficient technique has been recently found which consists of immersing the wafer investigated in a hydrofluoric acid solution [5-7]. Such chemical passivation leads to $S$ being drastically reduced whatever the doping level of the wafers and of the injection level. Values as low as $44 \mathrm{~cm} / \mathrm{s}$ were reported by Eikelboom et al. [7] for p type silicon with resistivities about 2 to $5 \Omega \mathrm{cm}$. However $\mathrm{HF}$ solutions are hazardous products which cannot be used during the long time needed to obtain a scan map. 


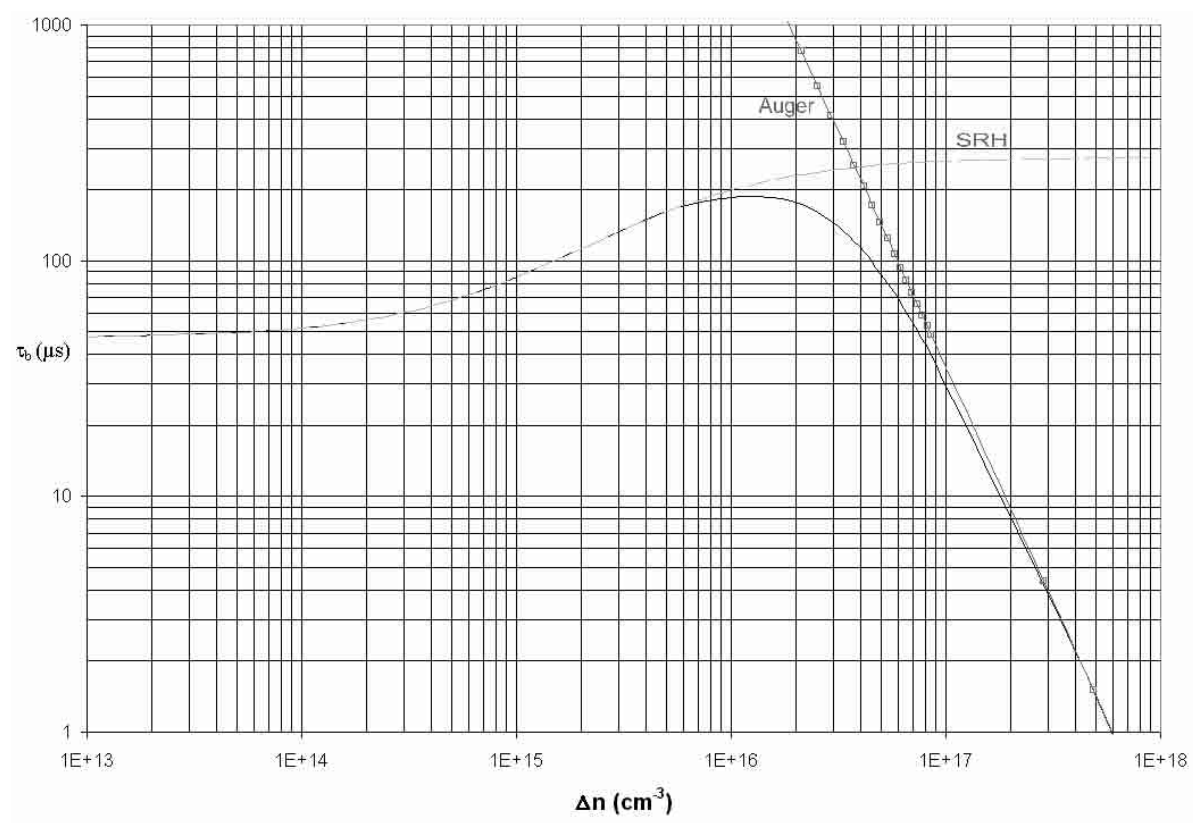

Fig. 1. Computed variations of the bulk lifetime $\tau_{\mathrm{b}}$ as a function of the excitation level, illustrating the contribution of Auger and $\mathrm{SRH}$ recombination lifetimes.

Horanyi et al. [8] have proposed an iodine-ethanol solution which passivates quite well $n$-type silicon surfaces and also, but to a lesser extent, $p$-type silicon surfaces. The use of this simple technique is unfortunately limited because the surface recombination velocity at the passivated surface and varies with time, which impedes the use of scanning techniques.

In this paper we present a new simple solution to passivate $p$-type silicon surfaces with an aqueous solution which could be used during lifetime measurements as well as during lifetime mapping. Minority carrier lifetime values are obtained by means of contactless techniques like the microwave detected photoconductance decay ( $\mu$ WPCD) and the phase shift (PS) technique. Lifetime scan maps obtained by means of the PS technique are compared with light beam induced current (LBIC) maps and are also correlated with the variations of deep trap densities determined by deep level transient spectroscopy (DLTS).

\section{Lifetime limiting factors}

Using the well-known expression of $\tau_{\mathrm{SRH}}$ given by the Shockley-Read-Hall (SRH) statistics and taking into account also Auger recombinations (as described in details in Ref. [2]) the bulk lifetime $\tau_{\mathrm{b}}$ can be computed as a function of the excitation level. The corresponding plot is displayed in Figure 1.

Considering the surface recombination velocity $S$, the measured lifetime value is an effective value given by $[2,9]$ :

$$
\frac{1}{\tau_{\mathrm{eff}}}=\frac{1}{\tau_{\mathrm{b}}}+D \beta^{2}
$$

with $\beta$ obtained from

$$
\beta \operatorname{tg}\left(\frac{\beta W}{2}\right)=\frac{S}{D}
$$

with $W$ the sample thickness and $D$ the carrier diffusion coefficient.

The computed variations of $\tau_{\text {eff }}$ with $S$ are displayed in Figure 2 for a $400 \mu \mathrm{m}$ thick sample and $\tau_{\mathrm{b}}$ varying in the range 10 to $200 \mu \mathrm{s}$. It is clear that surface recombination velocities higher than $100 \mathrm{~cm} / \mathrm{s}$ alter the measurement of the bulk lifetime, especially for $\tau_{\mathrm{b}} \geq 50 \mu \mathrm{s}$. Obviously the influence of $S$ on $\tau_{\text {eff }}$ is the higher the thickness of the wafer is the smaller.

As reported in [4] and [10], since the energy bands bend at the surface, it seems more realistic to use an effective surface recombination velocity defined at the edge of the space charge region close to the surface. Such an effective value $\left(S_{\text {eff }}\right)$ is injection level dependent and varies markedly with $\Delta n$. Consequently acceptable measurements can be done as long as small $\Delta n$ variations are ensured. Such requirement is easily fulfilled for $\tau_{\mathrm{b}}$, as shown in Figure 1, because $\tau_{\mathrm{b}}$ does not vary significantly provided $\Delta n<0.1 N_{\mathrm{A}}$, with $N_{\mathrm{A}}$ the acceptor concentration. This is not the case for $S_{\text {eff }}$, which varies markedly with $\Delta n$ [6], except under very small injection levels which reduce very often the signal to noise ratio in the experimental measurements. Indeed, $S_{\text {eff }}$ decreases by two orders of magnitude when $\Delta n$ varies from very low injection conditions $\left(\Delta n \leq 10^{-5} N_{\mathrm{A}}\right)$ to high injection levels $\left(\Delta n \geq N_{\mathrm{A}}\right)$. Notice that if the injection level could be controlled experimentally, $\tau_{\text {eff }}$ would be approximately close to $\tau_{\mathrm{b}}$ for $\Delta n=0.1 N_{\mathrm{A}}$, assuming that the initial value of $S_{\text {eff }}$ is not higher than $10^{4} \mathrm{~cm} / \mathrm{s}$. 


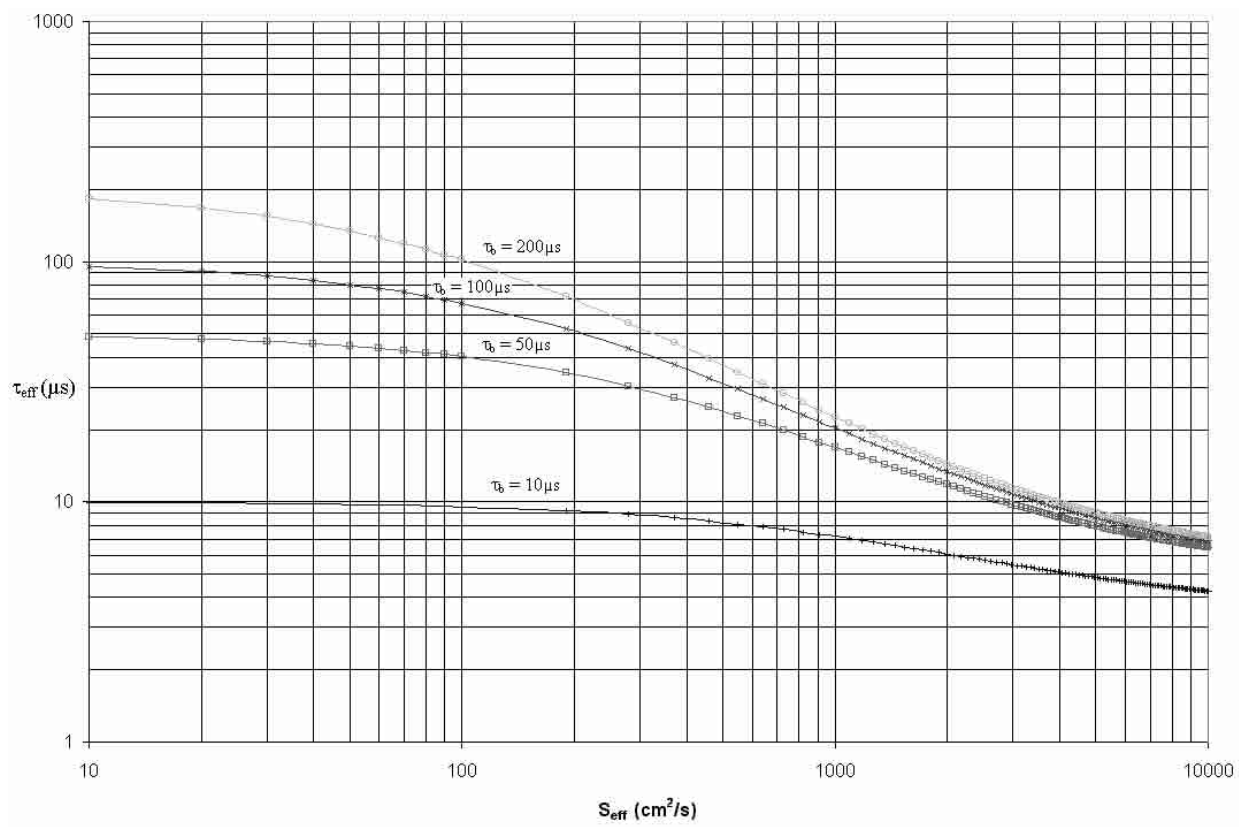

Fig. 2. Computed variations of effective lifetime $\tau_{\text {eff }}$ with surface recombination velocity when $\tau_{\mathrm{b}}$ varies in the range 10 to $200 \mu \mathrm{s}$ as indicated on the curves.

\section{Experimental}

The investigated materials were $p$-type float-zone (FZ) monocrystalline and multicrystalline (mc-Si) silicon wafers. The thickness of the samples varied in the range $200 \mu \mathrm{m}-2 \mathrm{~mm}$. Some FZ wafers were voluntarily contaminated by gold atoms according to the following sequences. Gold was first deposited on one surface by sputtering, then introduced in the sample by diffusion in pure argon at $750{ }^{\circ} \mathrm{C}$ for $90 \mathrm{~min}$. Then a layer of about $30 \mu \mathrm{m}$ was removed from both sides of the wafers in order to suppress surface segregation effects. Using the theoretical results given in [11-13], at $750{ }^{\circ} \mathrm{C}$ the gold concentration in the middle of the wafer should be:

$$
\begin{aligned}
N_{\text {Aus }}^{\mathrm{m}} & =3.53 \times 10^{24} \exp (-3.36 \mathrm{eV} / \mathrm{kT})\left[2(\pi t)^{1 / 2} / W\right] \\
& =5.33 \times 10^{11}(t)^{1 / 2}(400 / W)
\end{aligned}
$$

with $t$ in hours and $W$ in $\mu \mathrm{m}$.

According to equation (3), $N_{\text {Aus }}^{\mathrm{m}}$ should be about $9.3 \times$ $10^{11} \mathrm{~cm}^{-3}$ for a diffusion time of $90 \mathrm{~min}$.

The two techniques used to measure lifetimes are the microwave reflection detected photoconductance decay $(\mu \mathrm{WPCD})$, and the phase shift (PS). For the $\mu \mathrm{WPCD}$ technique, excess carriers are created by light pulses produced by a light emitting diode $(\lambda=950 \mathrm{~nm})$ and the variation of photoconductivity is monitored by microwave reflection. Microwaves from a Gunn diode at $9.4 \mathrm{GHz}$ frequency are directed onto the wafer through a circulator and a coaxial cable. The power of the microwaves reflected from the wafer is detected, amplified and displayed on an oscilloscope screen. The variation in reflected microwave power is proportional to the variation of wafer conductivity, i.e. to the excess carrier density.
Under such conditions, the penetration depth of the electromagnetic waves is about $500 \mu \mathrm{m}$ for resistivities around $1.6 \Omega \mathrm{cm}$ [14], and the absorption coefficient of the light for $\lambda=950 \mathrm{~nm}$ is $\alpha=1.6 \times 10^{2} \mathrm{~cm}^{-1}$ [15]. Consequently samples with usual thicknesses and doping levels can be investigated.

For the PS technique a laser diode beam intensity $(\lambda=942 \mathrm{~nm})$ was modulated by a sine wave form function generator. The phase shift between the optical excitation and the microwave reflected power was measured. As the excitation is modulated by small amplitude sine waves, the technique is a quasi steady state one, and its main advantage is that it allows work at a practically constant injection level. Moreover, trapping effects which can distort the measured lifetime values are reduced.

Figure 3 presents schematically the experimental set-up.

The relationship between phase shift $\phi$ and lifetime $\tau_{\mathrm{b}}$ as a function of $S$ (of both surfaces) and of the excitation frequency is given by equation (15) of reference [16] and expression (3) of reference [17]. The phase shift $\phi$ is a function of several parameters:

$$
\phi=F\left(S_{\mathrm{f}} ; S_{\mathrm{b}} ; D ; \tau_{\mathrm{b}} ; \alpha ; W ; f\right) .
$$

If three parameters are well-known ( $w, \alpha$ and frequency $f$ ), others are not: but $S_{\mathrm{f}}$ and $S_{\mathrm{b}}$ (surface recombination velocity of front side and backside surfaces, respectively) are assumed to be low and $D$ could be evaluated from the expression A5.3 of reference [2]. However for passivated surfaces and low excitation frequencies [9], the relationship is simplified and becomes

$$
-\operatorname{tg} \phi \cong \omega \tau_{\mathrm{eff}}
$$




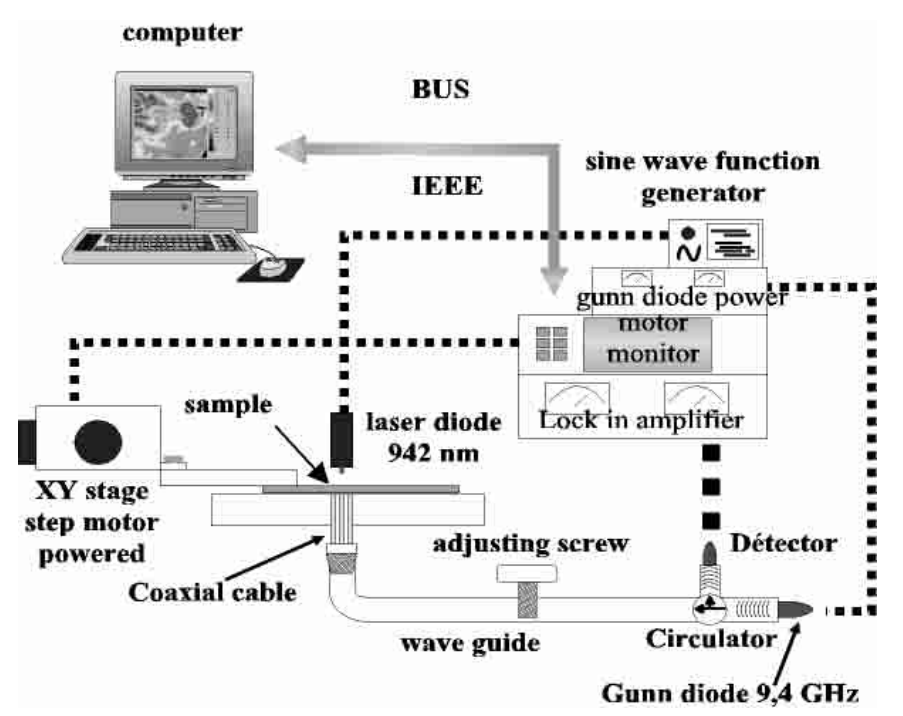

Fig. 3. Experimental set-up used in the phase shift technique. In order to obtain a scan map a thin coaxial cable and a focused light spot are used.

To obtain a lifetime scan map the laser beam was focused on the front surface of the sample and the spot diameter was about $50 \mu \mathrm{m}$. Microwaves were directed through a thin coaxial cable.

Surface passivation was obtained by immersing the sample in an aqueous solution of polyvidone during both the measurements and the mapping of the lifetime. Such a passivation effect a probably results of surface termination by hydrogen, like for the sample immersion in $\mathrm{HF}$ solution [6].

The samples were mounted on an $X-Y$ stage moved by computer controlled step motors, and they were allowed to slide above the end of the coaxial cable.

After $\tau_{\text {eff }}$ was measured, an array of metal-isolatorsemiconductor MIS diodes was made by evaporation of aluminium dots on the surface of FZ samples (thickness $200 \mathrm{~nm}$; diameter $1 \mathrm{~mm}$ ). These diodes were used for DLTS measurements in raw and gold contaminated FZ wafers.

The effective diffusion length $L_{\text {eff }}$ of minority carriers was determined by correlating the spectral variation of the steady state short-circuit photocurrent of (MIS) diodes with the spectral variation of $\alpha$. The diodes were prepared by deposition of a semitransparent $100 \AA$ thick aluminium layer (electron gun evaporation).

Scan maps of local values of $L_{\text {eff }}$ were obtained using the previously described light beam induced current technique (LBIC) [18], and compared with the lifetime scan maps.

After chemical etching by means of the Yang solution [19], which delineates extended crystallographic defects, optical micrographs of the multicrystalline scanned samples were obtained.

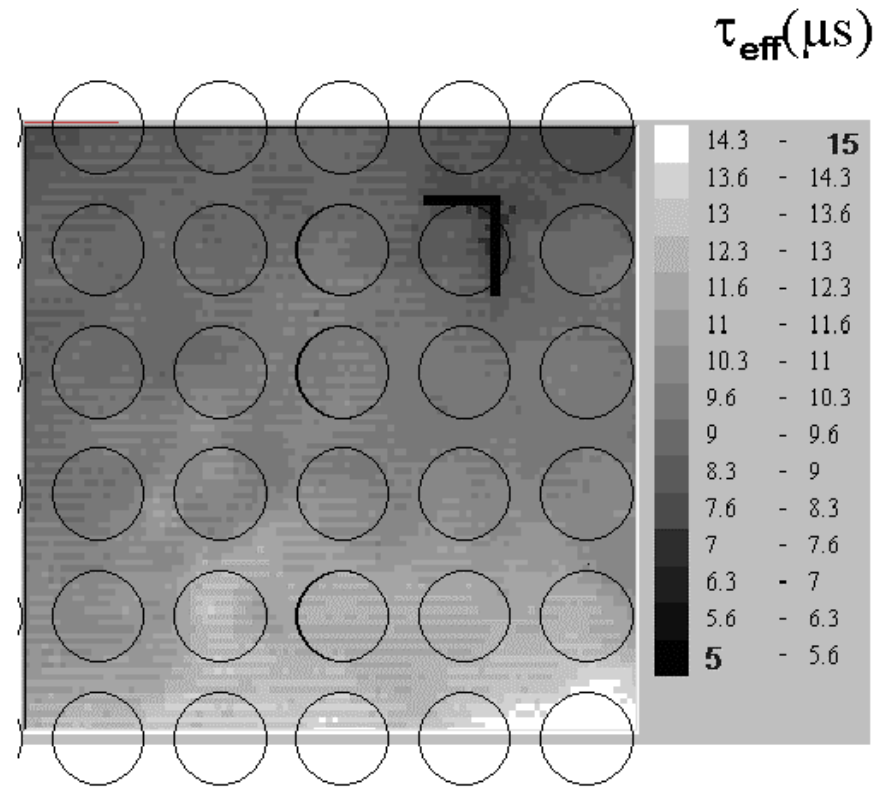

Fig. 4. Lifetime scan map of a gold contaminated FZ single crystal. Circles indicate the location of the MIS diodes used for DLTS.

\section{Results}

Preliminary verifications have shown that, for passivated and unpassivated surfaces, the PS values of $\tau_{\text {eff }}$ are in good agreement with the PCD values. When using the bevelled samples $S_{\text {eff }}$ is found to be below $10^{3} \mathrm{~cm} / \mathrm{s}$. When the samples are immersed in the aqueous solution of polyvidone, the passivation efficiency of the polyvidone solution is quite similar to that of the iodine-ethanol solution. Moreover, the aqueous solution is more stable than the iodine-ethanol one: there is no significative variation in the measure of the lifetime during $10 \mathrm{~h}$ at least.

The lifetime scan map of the gold contaminated FZ monocrystalline sample given in Figure 4, is not homogeneous, $\tau_{\text {eff }}$ varies from 5 to $15 \mu \mathrm{s}$. Such variations are in agreement with the variations of gold concentration $\left[\mathrm{Au}_{\mathrm{s}}\right]$ evaluated by DLTS; the values of $\left[\mathrm{Au}_{\mathrm{s}}\right]$ for each MIS diode made on the sample investigated are given in Figure 5 . The MIS diode positions are represented by circles in both Figures 4 and 5. The comparison of Figures 4 and 5 shows that the measured lifetime and gold concentrations vary as expected, i.e. $\tau_{\text {eff }}$ decreases when $\left[\mathrm{Au}_{\mathrm{s}}\right]$ increases. The measured values of $\tau_{\text {eff }}$ are in agreement with those computed from the local gold concentration when the capture cross section of the gold level for minority carriers is $2.7 \times 10^{-15} \mathrm{~cm}^{2}$ [20]. As the computed value is a bulk value, this result indicates that the measured $\tau_{\text {eff }}$ is close to $\tau_{\mathrm{b}}$, which is due to the fact that the surfaces have been sufficiently passivated by the polyvidone solution.

Effective diffusion length measurements confirm the preceding statement. Indeed, the mean values of $\tau_{\text {eff }}$ and $L_{\text {eff }}$, i.e. about $11 \mu \mathrm{s}$ and $120 \mu \mathrm{m}$, respectively, are in good agreement if we consider an electron diffusion coefficient of $13 \mathrm{~cm}^{2} \mathrm{~s}^{-1}$, which is an acceptable value in the contaminated crystal. This agreement suggests that $L_{\text {eff }}$ is 


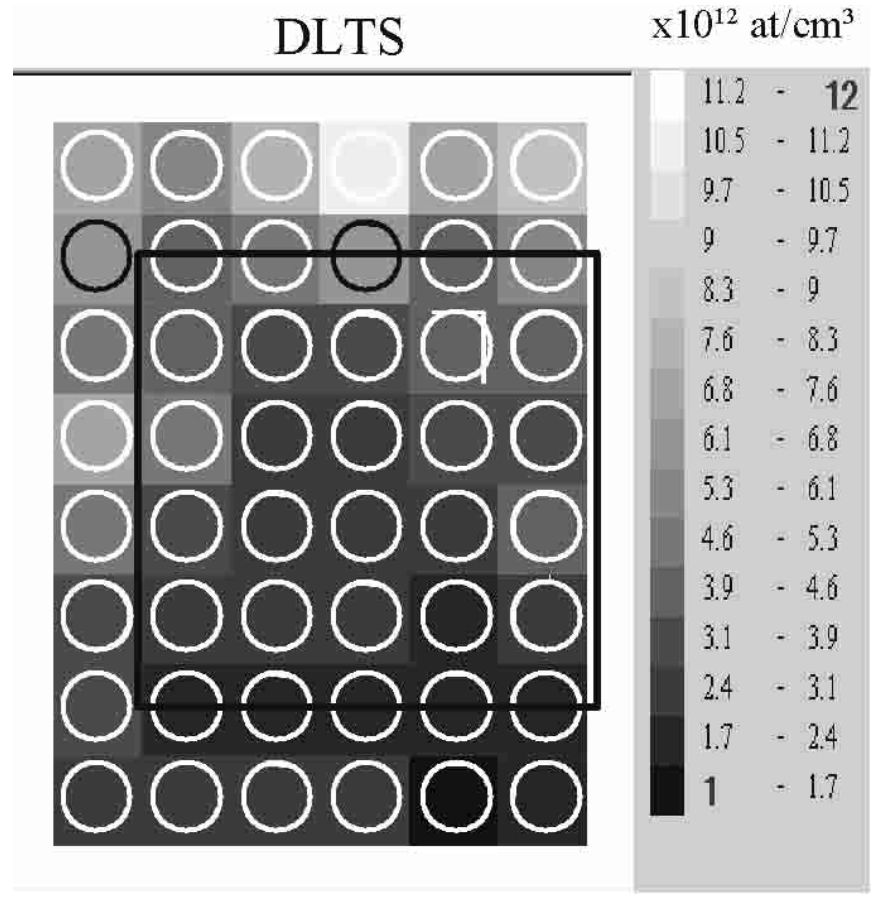

Fig. 5. Gold concentration found by DLTS by means of a MIS diode array made on the sample of Figure 4. Notice that the gold concentration varies as expected: it decreases when the lifetime increases (see Fig. 4).

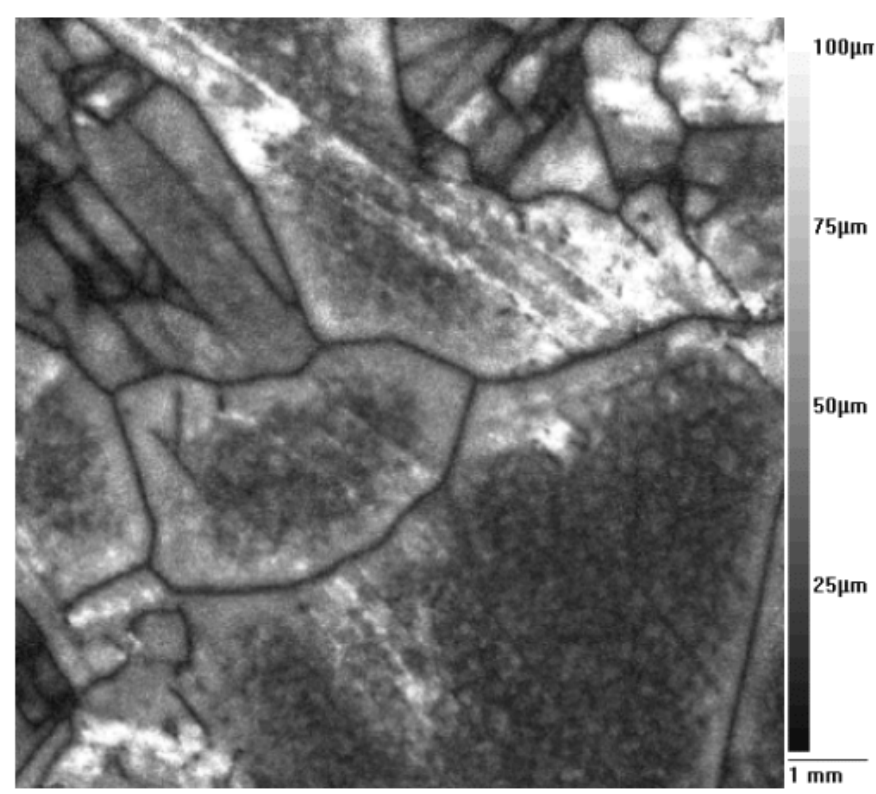

Fig. 6. Effective diffusion length scan map of a multicrystalline silicon wafer obtained by the LBIC technique, with a spatial resolution of about $10 \mu \mathrm{m}$.

close to $\tau_{\mathrm{b}}$ (thanks to noticeable passivation of the surfaces). This is due to the fact that $L_{\text {eff }}$ is less affected by the surface recombination than $\tau_{\text {eff }}$ - consequence of the MIS structure and of the wafer thickness being larger than $L_{\text {eff }}$ (little influence of the surfaces).

Figure 6 shows the $L_{\text {eff }}$ scan map for a multicrystalline silicon sample. Figure 7 shows the lifetime scan map

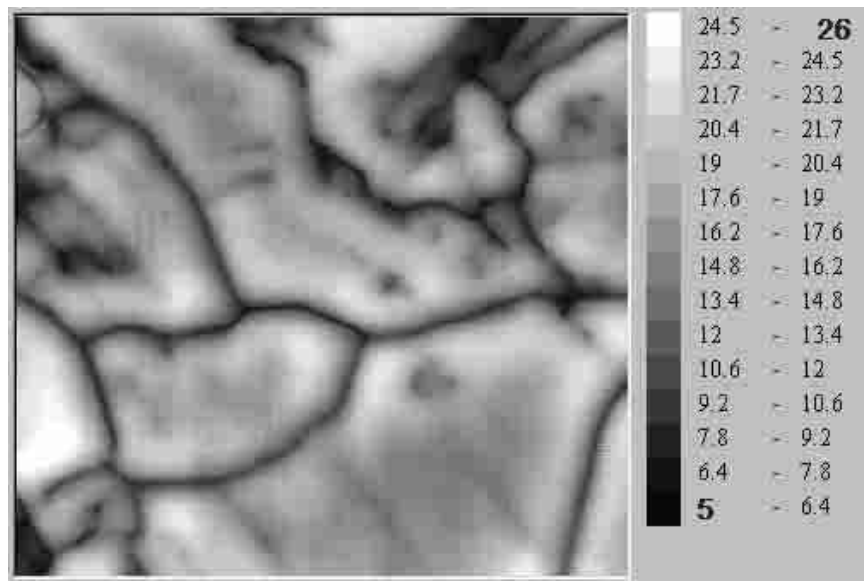

Fig. 7. Effective lifetime scan map of Figure 6 sample, whose surfaces have been passivated by means of an aqueous polyvidone solution.

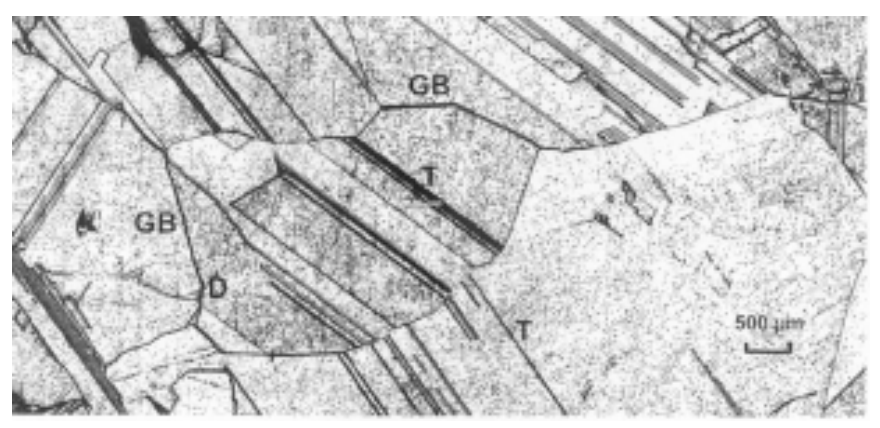

Fig. 8. Optical micrograph of the sample scanned in Figures 6 and 7 , after chemical etching which reveals grain boundaries and intragrain defects (mainly dislocations).

of the same sample whose surfaces have been passivated by the aqueous solution. $L_{\text {eff }}$ scan map is in agreement with the $\tau_{\text {eff }}$ one, both displaying the same features of extended crystallographic defects (grain boundaries (GB), twins $(\mathrm{T})$, dislocation lineages (D) and tangles (DT)). The values of $L_{\text {eff }}$ (Fig. 6 map) and those of $\tau_{\text {eff }}$ (Fig. 7 map) verify the relation $L_{\text {eff }}=\sqrt{D_{\mathrm{n}}} \tau_{\mathrm{n}}$, with an electron diffusion coefficient of about $8 \mathrm{~cm}^{2} / \mathrm{s}$, which is an acceptable value for such an imperfect material.

The multicrystalline sample has a measured lifetime which is certainly more related to the bulk lifetime than that of a monocrystal, because it contains a high density of different extended crystallographic defects, which is wellillustrated by the optical micrograph of Figure 8 obtained after chemical etching of the multicrystalline sample. Figures 6,7 and 8 display the same features of extended crystallographic defects.

Notice that the values of $\tau_{\text {eff }}$ and $L_{\text {eff }}$ are higher in the vicinity of GBs than in the center of the grains. The width of the improved zone is about a few hundreds of $\mu \mathrm{m}$. There is no correlation with the variations of intragrain defects densities and as $\tau_{\text {eff }}$ is sensitive to the presence of metallic impurities it could be emphasized that during the multicrystalline ingot growth, impurities (probably fast diffusers) are gettered by GBs. Such 
impurities can diffuse easily along few hundreds of $\mu \mathrm{m}$ during the cooling of the crystal. In such areas the impuritydefect interaction is reduced and the minority carrier diffusion length is higher.

\section{Conclusion}

We have shown that it is possible to measure the value of the minority carrier lifetime in silicon crystals, value close to the bulk value, thanks to the passivation of the wafer surfaces by immersion in an aqueous solution of polyvidone. The surface passivation is found to be stable during $10 \mathrm{~h}$ at least.

Using the phase shift between the sample excitation by a near infrared light spot and the reflected power of microwaves we obtained lifetime scan maps with a spatial resolution of $50 \mu \mathrm{m}$. Such a measurement technique is not invasive as it is contactless and as the polyvidone solution is easily removed.

For gold contaminated float zone single crystals the lifetime maps are in agreement with the variations of gold concentration evaluated by DLTS. Moreover the lifetime scan maps are in agreement with the minority carrier diffusion length maps of multicrystalline silicon wafers. Both maps help to detect the same features of extended crystallographic defects, and the values of the lifetime and of the diffusion length verify the relation $L_{\mathrm{n}}=\sqrt{D_{\mathrm{n}}} \tau_{\mathrm{n}}$.

Given that the fact that the lifetime scan maps are sensitive to the presence of metallic atoms like gold, it is suggested that further work should consist in developing a technique to detect and evaluate metal impurity concentrations in the range $10^{10}$ to $10^{12} \mathrm{~cm}^{-3}$ especially when such impurities are agglomerated or segregated at extended crystallographic defects.

The authors would like to thank CNRS-ECODEV (France) ADEME (France) and Commission of European Union (CONTRACT JOULE III - "SICOCELL" JOR3-CT 97- 0165) for financial supports.

\section{References}

1. J. Lagowski, P. Edelman, M. Dexter, W. Henley, Semicond. Sci. Technol. 7, A185 (1992).

2. D.K. Schroder, in Semiconductor Material and Device Characterization (Wiley Interscience Publication-NewYork, 1990), p. 359.

3. L. Cai, A. Rohatgi, S. Han, G. May, J. Appl. Phys. 83, 5885 (1998).

4. J. Schmidt, A.G. Aberle, J. Appl. Phys. 81, 6186 (1997).

5. T.M. Buck, F.S. Mc. Kim, J. Electrochem. Soc. 135, 709 (1988).

6. E. Yablonovitch, T. Gmitter, Appl. Phys. Lett. 49, 587 (1986).

7. J.A. Eikelboom, C. Leguijt, C.F.A. Fruman, A. Burgers, Sol. Energy Mater. Sol. Cells 36, 169 (1995).

8. T.S. Horanyi, T. Pavelka, P. Tüttö, Appl. Surf. Sci. 63, 306 (1993).

9. J.W. Orton, P. Blood, in The Electrical Characterization of Semiconductors: Measurements of Minority Carrier Properties (Academic Press London, 1990), pp. 71-122.

10. A.G. Aberle, S. Glunz, W. Warta, J. Appl. Phys. 71, 4422 (1992).

11. U. Gösele, W. Frank, A. Seeger, Appl. Phys. Lett. 23, 361 (1980).

12. E. Yakimov, G. Mariani, B. Pichaud, J. Appl. Phys. 78, 1495 (1995).

13. N.A. Stolwijk, B.J. Holzl, W. Frank, E.R. Weber, H. Mehrer, Appl. Phys. 139, 37 (1986).

14. R.K. Ahrenkiel, S. Johnston, Sol. Energy Mater. Sol. Cells 55, 59 (1998).

15. E.S. Nartowitz, A.M. Goodman, J. Electrochem. Soc. 132, 2292 (1985).

16. M. Orgeret, J. Boucher, Rev. Phys. Appl. 13, 29 (1978).

17. A. Schönecker, J.A. Eikelboom, A.R. Burgers, P. Lölgen, C. Leguijt, W.C. Sinke, J. Appl. Phys. 79, 1497 (1996).

18. M. Stemmer, S. Martinuzzi, Inst. Phys. Conf. Ser. 135, 239 (1993).

19. D.K. Schroder, in reference [2] p. 457.

20. K. Graff, in Metal Impurities in Silicon Device Fabrication, Springer series in Materials Sciences, Vol. 24 (Springer Verlag Berlin, 1995), pp. 108-109. 